\title{
Planthopper-Secreted Salivary Calmodulin Acts as an Effector for Defense Responses in Rice
}

\author{
Jianmei Fu't, Yu Shi't, Lihua Wang ${ }^{1 \dagger}$, Tian Tian', Jing Li', Lei Gong', Zhouting Zheng', \\ Maofeng Jing', Jichao Fang ${ }^{1,2,3 *}$ and Rui Ji ${ }^{1,3 *}$ \\ 1 Institute of Plant Protection, Jiangsu Academy of Agricultural Sciences, Jiangsu Key Laboratory for Food Quality \\ and Safety-State Key Laboratory Cultivation Base of Ministry of Science and Technology, Nanjing, China, ${ }^{2}$ College of Plant \\ Protection, Nanjing Agricultural University, Nanjing, China, ${ }^{3}$ Jiangsu Collaborative Innovation Center of Regional Modern \\ Agriculture and Environmental Protection, Huaiyin Normal University, Huai'an, China
}

\section{OPEN ACCESS}

Edited by:

Zuhua He,

Center for Excellence in Molecular

Plant Sciences (CAS), China

Reviewed by:

Jiancai Li,

Key Laboratory of Insect

Developmental and Evolutionary Biology, Institute of Plant Physiology and Ecology, Shanghai Institutes for Biological Sciences (CAS), China Tianbo Ding,

Qingdao Agricultural University, China

*Correspondence:

Rui Ji

jirui@jaas.ac.cn

Jichao Fang

fangjc@jaas.ac.cn

tThese authors have contributed equally to this work

Specialty section:

This article was submitted to Plant Pathogen Interactions, a section of the journal

Frontiers in Plant Science

Received: 22 December 2021

Accepted: 07 February 2022

Published: 28 February 2022

Citation:

Fu J, Shi Y, Wang L, Tian T, Li J,

Gong $L$, Zheng Z, Jing M, Fang $J$ and

Ji R (2022) Planthopper-Secreted

Salivary Calmodulin Acts as an

Effector for Defense Responses

in Rice. Front. Plant Sci. 13:841378.

doi: 10.3389/fp/s.2022.841378
The brown planthopper (Nilaparvata lugens, BPH) and small brown planthopper (Laodelphax striatellus, SBPH) are major pests of rice (Oryza sativa) in Asia. These piercing-sucking insects secrete saliva into the host during feeding. Nevertheless, it is largely unknown how planthoppers use salivary effectors to enable continuous feeding on rice. Here, we screened their salivary proteomes and selected eight salivary proteins conserved between SBPH and BPH as candidate effectors. Silencing calmodulin (CaM) impeded BPH and SBPH from penetrating the phloem. Hence, their food intake, survival, and fecundity on rice plants were reduced. By contrast, CaM silencing had a small effect on the survival rate of $\mathrm{BPH}$ and $\mathrm{SBPH}$ raised on artificial diet. The CaM amino acid sequences were the same for both BPH and SBPH. CaM was highly expressed in their salivary glands and secreted into the rice plants during feeding. Bacterially expressed recombinant CaM protein exhibited calcium-binding activity. In planta expression disclosed that CaM was localized to the plant cytoplasms and nuclei and suppressed plant defenses such as hydrogen peroxide $\left(\mathrm{H}_{2} \mathrm{O}_{2}\right)$ accumulation and callose deposition. CaM-silenced $\mathrm{BPH}$ and SBPH nymphs elicited relatively high levels of $\mathrm{H}_{2} \mathrm{O}_{2}$ and callose accumulation in rice plants. The foregoing results reveal that $\mathrm{CaM}$ is an effector as it enables the planthopper to reach the phloem by suppressing callose deposition and $\mathrm{H}_{2} \mathrm{O}_{2}$ accumulation in rice.

Keywords: calmodulin (CaM), effector, planthopper, plant-insect interaction, rice defense response

\section{INTRODUCTION}

Plants and herbivorous insects have been engaged in a long-term arms race. Plants have developed defensive mechanisms, but insects have evolved various strategies to counteract them. Plant cells can perceive herbivore-associated molecular patterns, rapidly elevate their cytosolic calcium $\left(\mathrm{Ca}^{2+}\right)$ concentrations, a universal secondary messenger in eukaryotic organisms, and activate various defense responses such as phytohormone and hydrogen peroxide $\left(\mathrm{H}_{2} \mathrm{O}_{2}\right)$ biosynthesis and sieve tube plugging (Arimura and Maffei, 2010; Ranf et al., 2011). While feeding, however, insects inject several salivary effectors into host plant cells and interfere with these host plant defenses (Ji et al., 2017, 2021; Ye et al., 2017; Huang et al., 2019; Tian et al., 2021). The identification 
of insect salivary proteins may help elucidate the mechanisms by which insects modulate host plant defenses. Recent research has generated abundant information regarding insect effectors and elicitors, especially those produced by piercing-sucking insects. These substances may positively (Ji et al., 2017, 2021; Ye et al., 2017; Huang et al., 2019; Wang et al., 2019; Xu et al., 2019; Tian et al., 2021) or negatively (Bos et al., 2010; Chaudhary et al., 2014; Rao et al., 2019; Guo et al., 2020) affect insect feeding performance on plant hosts. Such interactions resemble those occurring between microbial pathogens and their host plants.

The accumulation of $\mathrm{H}_{2} \mathrm{O}_{2}$ and cell wall polymer callose are common and effective plant defenses against sap-sucking insects including rice planthoppers. $\mathrm{H}_{2} \mathrm{O}_{2}$ is associated with lignin formation in cell wall, and inhibits insects feeding (Rasool et al., 2017). The deposition of the $\beta-1,3$ glucan polymer callose on the sieve plates causes sieve element sealing, and prevents insects from sucking phloem sap (Hao et al., 2008). When certain salivary effectors are secreted into plants, they attenuate these host defense mechanisms (Zhou et al., 2009; Ye et al., 2017; Huang et al., 2019; Su et al., 2019; Guo et al., 2020; Wang et al., 2020). For example, the mixture of aphid watery salivary proteins prevents $\mathrm{Ca}^{2+}$-dependent sieve elements plugging (Will et al., 2007). Salivary Mp55 from the aphid and LsDNase II from the planthopper suppresses insect-elicited callose deposition and $\mathrm{H}_{2} \mathrm{O}_{2}$ accumulation (Elzinga et al., 2014; Huang et al., 2019). The planthopper salivary effectors, such as vitellogenin and $\mathrm{Ca}^{2+}$. binding proteins, reported in our previous studies (Ye et al., 2017; Ji et al., 2021; Tian et al., 2021) suppress insect-elicited $\mathrm{H}_{2} \mathrm{O}_{2}$ accumulation by interacting with a plant immunity regulator and binding free $\mathrm{Ca}^{2+}$, respectively. Glutathione peroxidase from the mirid bug and ferritin from the whitefly suppress the plant $\mathrm{H}_{2} \mathrm{O}_{2}$ signaling pathway (Su et al., 2019; Dong et al., 2020).

The brown (Nilaparvata lugens, BPH) and small brown (Laodelphax striatellus, SBPH) planthoppers are sap-sucking insects that directly feed on rice (Oryza sativa) phloem and indirectly transmit viruses to the host. Hence, planthoppers cause major annual rice grain yield losses (Otuka et al., 2010). Saliva proteomic analyses identified certain salivary proteins from the two foregoing planthopper species (Huang et al., 2016, 2018; Fu et al., 2021). A few successive defense/counter-defense mechanisms may be observed in $\mathrm{BPH}, \mathrm{SBPH}$, and rice, and they illustrate the co-evolutionary processes underlying riceplanthopper interactions (Ji et al., 2017, 2021; Ye et al., 2017; Shangguan et al., 2018; Huang et al., 2019; Huang J. et al., 2020; Fu et al., 2021; Tian et al., 2021). In some cases, $\mathrm{Ca}^{2+}$ is required for the accumulation of $\mathrm{H}_{2} \mathrm{O}_{2}$ and callose in plant (Hayashi et al., 1987; Zuppini et al., 2004). Salivary elicitors disulfide isomerase (LsPDI1) and mucin-like protein from planthoppers induce plant immune responses including cell death, $\mathrm{H}_{2} \mathrm{O}_{2}$, and callose accumulation that depend on the $\mathrm{Ca}^{2+}$ signaling pathway (Shangguan et al., 2018; Rao et al., 2019; Huang J. et al., 2020; Fu et al., 2021). Conversely, two $\mathrm{Ca}^{2+}$-binding proteins in the saliva of planthoppers attenuate $\mathrm{Ca}^{2+}$-triggered $\mathrm{H}_{2} \mathrm{O}_{2}$ biosynthesis by binding free $\mathrm{Ca}^{2+}$ in host rice (Ye et al., 2017; Tian et al., 2021). In aphids, injection of salivary $\mathrm{Ca}^{2+}$-binding proteins into hosts might be a universal mechanism for preventing sieve plate occlusion (Will et al., 2009). Nevertheless, certain salivary
$\mathrm{Ca}^{2+}$-binding protein in phloem feeders including planthoppers preventing sieve tube occlusion, including callose deposition, remain to be established.

Interestingly, analysis of the saliva proteomes (Huang et al., 2018; Fu et al., 2021) and previously reported effectors from $\mathrm{BPH}$ and SBPH revealed that most of the effectors are, in fact, conserved salivary proteins. Here, we aimed principally at the eight salivary proteins conserved between SBPH and $\mathrm{BPH}$ to screen for candidate planthopper effectors. The RNA interference (RNAi) approach disclosed that only calmodulin (CaM) contributed to $\mathrm{SBPH}$ and $\mathrm{BPH}$ feeding. CaM has been detected in the saliva proteomes of various piercing-sucking herbivorous arthropods such as aphids, whiteflies, and spider mites but not yet in those of planthoppers (Huang et al., 2018; Huang H. J. et al., 2020; Fu et al., 2021). Therefore, CaM might play an important role in herbivore-plant interactions. Subsequent analyses demonstrated that CaM has an effector function and may facilitate planthoppers continuous feeding by inhibiting callose deposition and $\mathrm{H}_{2} \mathrm{O}_{2}$ accumulation in host rice plants. Thus CaM is a good candidate for RNAi-based planthoppers management.

\section{MATERIALS AND METHODS}

\section{Plant Growth and Insect Rearing}

Pre-germinated Xiushui 11 rice seeds were germinated in plastic bottles in a greenhouse at $28 \pm 2{ }^{\circ} \mathrm{C}$ under a $14 \mathrm{~h}$ light $/ 10 \mathrm{~h}$ dark photoperiod. Each 7-day-old seedling was then transferred to a $750 \mathrm{~mL}$ plastic pot containing potting medium. After 25 days, the rice plants were ready for use in the subsequent experiments. Nicotiana benthamiana was kept in a climate chamber at $23 \pm 1^{\circ} \mathrm{C}$ under a $16 \mathrm{~h}$ light $/ 8 \mathrm{~h}$ dark photoperiod. After $4-$ 5 weeks (five-leaf stage), the plants were used in the subsequent Agrobacterium tumefaciens-mediated transient transformation experiments. The original SBPH colonies were obtained from rice fields in Nanjing, China and maintained on rice seedlings in a climate chamber at $25 \pm 1^{\circ} \mathrm{C}$ under a $14 \mathrm{~h}$ light $/ 10 \mathrm{~h}$ dark photoperiod. To minimize interference from egg deposition, fourth-instar nymphs were injected and metamorphosed into fifth-instar nymphs 2 days later, and the latter were used for rice defense response analyses. Injected third-instar nymphs were used for the survival analysis. Newly emerged brachypterous female adults within $24 \mathrm{~h}$ were used for honeydew excretion measurement and electrical penetration graph (EPG) analysis, owing to the highest feeding capacity at this stage.

\section{RNA Preparation and Quantitative Polymerase Chain Reaction}

Total RNA was extracted from whole bodies of the first- to fifth-instar nymphs and newly emerged brachypterous male and female adults. It was also extracted from salivary glands, guts, ovaries, fat bodies, and integuments dissected from brachypterous female adults. For each biological replicate, 50 nymphs, 20 adults, and various tissues from 200 brachypterous female adults were collected. Each experiment was repeated 
in triplicate. Total RNA was isolated with the SV Total RNA Isolation System (Promega, Madison, WI, United States) according to the manufacturer's instructions. After DNase treatment and quantification, $1 \mu \mathrm{g}$ total RNA sample was reversetranscribed with a PrimeScript RT-PCR Kit (TaKaRa Bio Inc., Dalian, China). The quantitative polymerase chain reaction (qPCR) reactions were performed with a TB Green ${ }^{\mathrm{TM}}$ Premix Ex Taq ${ }^{\mathrm{TM}}$ Kit (TaKaRa Bio Inc.) according to the manufacturer's protocol and run in a LightCycler ${ }^{\circledR} 480$ II Real Time System (Roche Diagnostics, Basel, Switzerland). Elongation factor $2 \alpha$ (ef2) served as the internal normalization controls. The qPCR primers are listed in Supplementary Table 1. The gene expression levels were calculated by normalizing the target gene mRNA level to ef 2 mRNA abundance via the $2^{-\Delta \mathrm{Ct}}$ method (Chyla et al., 2019; Tian et al., 2021).

\section{Gene Cloning and Vector Construction}

LsCaM and NlCaM (GenBank no. RZF46934.1 and AXY40108.1) were obtained by reverse transcription polymerase chain reaction (RT-PCR) using total RNA from SBPH and BPH. They were cloned into the pMD19-T vector (TaKaRa Bio Inc., Kusatsu, Japan), and sequenced. An In-Fusion HD Cloning Kit (TaKaRa Bio Inc.) was used to insert $L s C a M$ into the pBINPLUS-green fluorescent protein (GFP) vector (subcellular localization and expression) via a single BamHI digestion site. LsPDI1 was cloned via homologous recombination into the pBINPLUS-mCherry vector (expression) via a single BamHI digestion site using the aforementioned kit. Primers are listed in Supplementary Table 1.

\section{Double Stranded RNA Synthesis and Injection in Planthoopers}

Primers containing the T7 promoter (Supplementary Table 1) were designed to clone a specific fragment ( 300-500 bp) in each target gene. The double stranded RNA (dsRNA) was synthesized and microinjected as previously described (Liu et al., 2010; Ji et al., 2017). To determine RNAi efficiency, target gene expression was measured at 2, 4, and 6 days after dsRNA injection. qPCR was repeated three times with six replicates per time, there were 20 insects per replicate.

\section{Planthopper Bioassays}

Planthopper feeding behavior was recorded on a direct-current EPG system (Wageningen Agricultural University). The method used was previously described (Cao et al., 2013; Ji et al., 2017). The feeding behavior of newly emerged adult females 2 days after dsRNA injection was monitored for $6 \mathrm{~h}$. There were 15 replicates per treatment. The recorded signals were analyzed with PROBE software (Wageningen Agricultural University). The durations of each sequential waveform event were measured for each insect. The average waveform duration per insect per waveform was calculated for each treatment.

Honeydew excretion reflects feeding activity in sap-sucking insects. To assess the effect of CaM knockdown on planthopper honeydew excretion, one rice stem was covered with an inverted transparent plastic cup placed on a filter paper. Three days after injection, a single newly emerged brachypterous female adult was transferred to the cup and left to feed for 2 days. The filter papers were then soaked in $0.1 \%(\mathrm{w} / \mathrm{v})$ ninhydrin in acetone and oven-dried at $65^{\circ} \mathrm{C}$ for $30 \mathrm{~min}$. The honeydew stains appeared as violet or purple spots because of their amino acid content (Lei et al., 2014; Ji et al., 2021). The areas of the ninhydrinpositive deposits were measured with ImageJ v. 1.8.0 (National Institutes of Health, Bethesda, MD, United States). There were 15 replicates per treatment.

The injected third-instar nymphs were left to recover on rice seedlings for 1 day. Healthy nymphs were randomly selected for the subsequent survival bioassay on rice plants or artificial diet. One rice stem per pot was confined within a glass cylinder (diameter, $2 \mathrm{~cm}$; height, $8 \mathrm{~cm}$ ) containing 20 third-instar nymphs. In the artificial diet experiment, 20 third-instar nymphs were introduced into individual feeding chambers (diameter, $2 \mathrm{~cm}$; long, $9 \mathrm{~cm}$ ) as described previously (Ji et al., 2017). The surviving nymphs were counted daily. The survival rate of each treatment and the corrected survival rates of nymphs with injected $d s L s C a M$, using nymphs with injected $d s G F P$ as controls, on rice or artificial diet were calculated. The experiment was repeated five times.

The number of eggs laid per female adult was determined using a previously reported method (Ji et al., 2017). A single newly emerged dsRNA-treated female adult and two newly emerged untreated male adults were released into the same glass cylinder confining a single rice stem. The insects were allowed to feed for 8 days. The number of eggs laid by a female adult on each dissecting rice stem was counted under a microscope (Olympus SZ51, Olympus Corp., Tokyo, Japan). There were 15 replicates per treatment.

\section{Calmodulin Sequence Analysis}

Signal peptides and transmembrane and EF-hand domains were predicted with SignalP v. 5.0, ${ }^{1}$ TMHMM v. 2.0, ${ }^{2}$ and PROSITE, ${ }^{3}$ respectively.

\section{$\mathrm{Ca}^{2+}$-Binding Assays}

The complete open reading frame (CORF) of $L s C a M$ was cloned into a pET-28a vector (Novagen, Madison, WI, United States). The LsCaM:pET-28a construct was transformed into Escherichia coli BL21 (DE3). The recombinant protein products were purified with Ni-NTA columns (Qiagen, Venlo, Netherlands) according to the manufacturer's instructions. They were then concentrated with a YM-3 Microcon centrifugal filter device (EMD Millipore, Billerica, MA, United States).

The $\mathrm{Ca}^{2+}$-binding property of the recombinant $\mathrm{CaM}$ was determined by gel mobility shift assay as previously described (Anisuzzaman et al., 2010; Hattori et al., 2012; Ye et al., 2017; Tian et al., 2021). Briefly, $0.75 \mu \mathrm{g}$ CaM was mixed with equal volumes of $0.5 \mathrm{mM} \mathrm{CaCl}_{2}, 0.15 \mathrm{mM} \mathrm{CaCl}_{2}, 0.05 \mathrm{mM} \mathrm{CaCl}_{2}$, $0.015 \mathrm{mM} \mathrm{CaCl}_{2}$, or $0.5 \mathrm{mM}$ ethylenediaminetetraacetic acid (EDTA). Each mixture was incubated at $25^{\circ} \mathrm{C}$ for $30 \mathrm{~min}$,

\footnotetext{
${ }^{1}$ http://www.cbs.dtu.dk/services/SignalP/

${ }^{2}$ http://www.cbs.dtu.dk/services/TMHMM/

${ }^{3}$ http://prosite.expasy.org/
} 
combined with Laemmli sample buffer, and subjected to SDSPAGE with no heating.

\section{Western Blotting}

Proteins were extracted from the salivary glands of 100 fifthinstar SBPH or BPH nymphs, and from the leaf sheaths of rice steams confined within ventilated glass cylinders containing 200 fifth-instar nymphs that had been removed after 2 days. Leaf sheaths from rice stems in empty glass cylinders served as negative controls. The outer three leaf sheaths of each rice stem were harvested and pulverized in liquid nitrogen. Then $2 \mathrm{~mL}$ NP40 buffer (Beyotime Institute of Biotechnology, Shanghai, China) was added and the suspension was vortexed at $4^{\circ} \mathrm{C}$ for $20 \mathrm{~min}$. Each sample was centrifuged at $15,200 \times g$ and $4^{\circ} \mathrm{C}$ for $5 \mathrm{~min}$. Each supernatant was collected and concentrated to $200 \mu \mathrm{L}$ with a YM-3 Microcon centrifugal filter device (EMD Millipore, Billerica, MA, United States). The samples were subjected to SDS-PAGE on a $12 \%(\mathrm{w} / \mathrm{v})$ gradient gel (Bio-Rad Laboratories, Hercules, CA, United States) and transferred onto a polyvinylidene difluoride (PVDF) membrane. Western blotting was performed using primary antibody (1:2,000 dilution) and visualized with the VersaDoc imaging system (Bio-Rad Laboratories) as previously described (Ji et al., 2017; Tian et al., 2021).

\section{Transient Calmodulin Expression in Nicotiana benthamiana and Rice Protoplast}

Empty pBINPLUS-GFP or pBINPLUS-mCherry vector or their recombinant plasmids harboring CaM or LsPDI1 were transformed by electroporation into $A$. tumefaciens GV3101. The A. tumefaciens was re-suspended in an infiltration buffer $(10 \mathrm{mM} \mathrm{MgCl} 2,500 \mathrm{mM} \mathrm{MES}$, and $100 \mathrm{mM}$ acetosyringone). At a final $O D_{600}=0.4$, the A. tumefaciens was infiltrated into $N$. benthamiana leaves with a needleless syringe as previously described (Dong et al., 2020; Ji et al., 2021). The CaM-GFP was expressed for $24 \mathrm{~h}$, then LsPDI1-mCherry was infiltrated into the same region. GFP $(488 \mathrm{~nm})$ and mCherry $(561 \mathrm{~nm})$ fluorescence signals were observed under a Zeiss LSM750 confocal laser-scanning microscope (CLSM; Carl Zeiss AG, Oberkochen, Germany). At $24 \mathrm{~h}$ post-LsPDI1 infiltration, the infiltrated $N$. benthamiana leaves were collected, and vacuum-infiltrated with $1 \mathrm{mg} \mathrm{mL}^{-1} 3,3^{\prime}$-diaminobenzidine (DAB, pH 7.2), and incubated overnight in the dark, and decolorized with trichloroacetaldehyde. DAB staining was performed on 20 leaves.

Rice protoplasts were isolated and transfected as previously described (Zhang et al., 2011; Ji et al., 2021). Briefly, 10-dayold rice seedlings were cut into $0.5 \mathrm{~mm}$ segments, transferred to $0.6 \mathrm{M}$ mannitol, and incubated in the dark for $30 \mathrm{~min}$. The plasmolyzed tissues were transferred to a mixture comprising 1.5\% (w/v) Cellulase R-10 (Yakult Honsha, Tokyo, Japan), 0.75\% (w/v) Macerozyme R-10 (Yakult Honsha), 0.5 M mannitol, $10 \mathrm{mM}$ MES ( $\mathrm{pH}$ 5.7), 0.1\% (v/v) bovine serum albumin
(BSA), $10 \mathrm{mM} \mathrm{CaCl}$, and $5 \mathrm{mM} \beta$-mercaptoethanol for cell wall degradation. Polyethylene glycol-mediated transfection was used to transform the recombinant vector with $2 \times 10^{6}$ rice protoplasts. They were incubated in the dark for $16 \mathrm{~h}$, and their green fluorescence was examined under a Zeiss LSM750 CLSM (Carl Zeiss AG).

\section{Callose Staining}

Infiltrated tobacco leaf disks and planthopper-infested rice leaf areas were stained with aniline blue to visualize callose deposition as previously described (Bing et al., 2012; Fu et al., 2021). Briefly, treated samples were subjected to $0.05 \%(\mathrm{w} / \mathrm{v})$ aniline blue staining for $2 \mathrm{~h}$ followed by $2.5 \mathrm{~g} / \mathrm{mL}$ trichloroacetic acid decolorization. The treated samples were observed and photographed under a Zeiss LSM750 CLSM (Carl Zeiss AG) fitted with a UV filter. Fluorescence was quantified with ImageJ v. 1.8.0 (NIH). Each treatment was scored for 20 randomly selected microscopic fields. Each experiment was repeated six times.

\section{$\mathrm{H}_{2} \mathrm{O}_{2}$ Analysis}

Samples were prepared for $\mathrm{H}_{2} \mathrm{O}_{2}$ analysis as previously described (Lou and Baldwin, 2006; Ji et al., 2017, 2021; Ye et al., 2017). Each single rice stem was confined in a glass cylinder containing 30 fifth-instar nymphs that had been injected with the double stranded RNA of LsCAM (dsLsCAM) or GFP (dsGFP) 2 days earlier. The outer two leaf sheaths of each stem were harvested at various time points after the treatment. Infiltrated $N$. benthamiana leaf disks and rice leaf sheath samples were collected for $\mathrm{H}_{2} \mathrm{O}_{2}$ measurement. $\mathrm{H}_{2} \mathrm{O}_{2}$ concentration was determined with an Amplex-Red Hydrogen Peroxide/Peroxidase Assay Kit (Invitrogen, Carlsbad, CA, United States) (Lou and Baldwin, 2006). Each experiment was repeated six times.

\section{Data Analysis}

Differences in insect bioassay, genes expression, and $\mathrm{H}_{2} \mathrm{O}_{2}$ content among treatments were analyzed by one-way ANOVA followed by Duncan's multiple range tests for multiple treatment comparisons or by Student's $t$-tests for pairwise treatment comparisons. Data analyses were performed using Statistica v. 6 (SAS Institute Inc., Cary, NC, United States).

\section{RESULTS}

\section{Effect of Silencing Salivary Protein-Encoding Genes on Small Brown Planthopper Survival}

The conserved salivary proteins CaM, enolase, stubble-2, placental protein 11 (PP11), $\alpha-N$-acetylgalactosaminidase (NAGA), carboxylesterase, regucalcin, and trypsin-26 were selected for RNAi application in SBPH nymphs. Phenotypic variation was observed at $24 \mathrm{~h}$ intervals. Morphological defect and lethality were virtually undetectable in the $d s G F P$ injected SBPH nymph control throughout the test period. The suppression of LsCaM or Lsenolase transcription was 


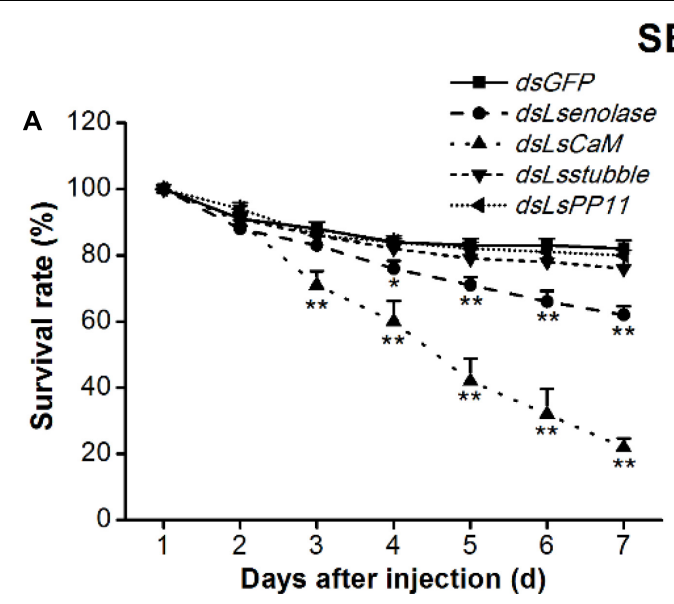

\section{SBPH}
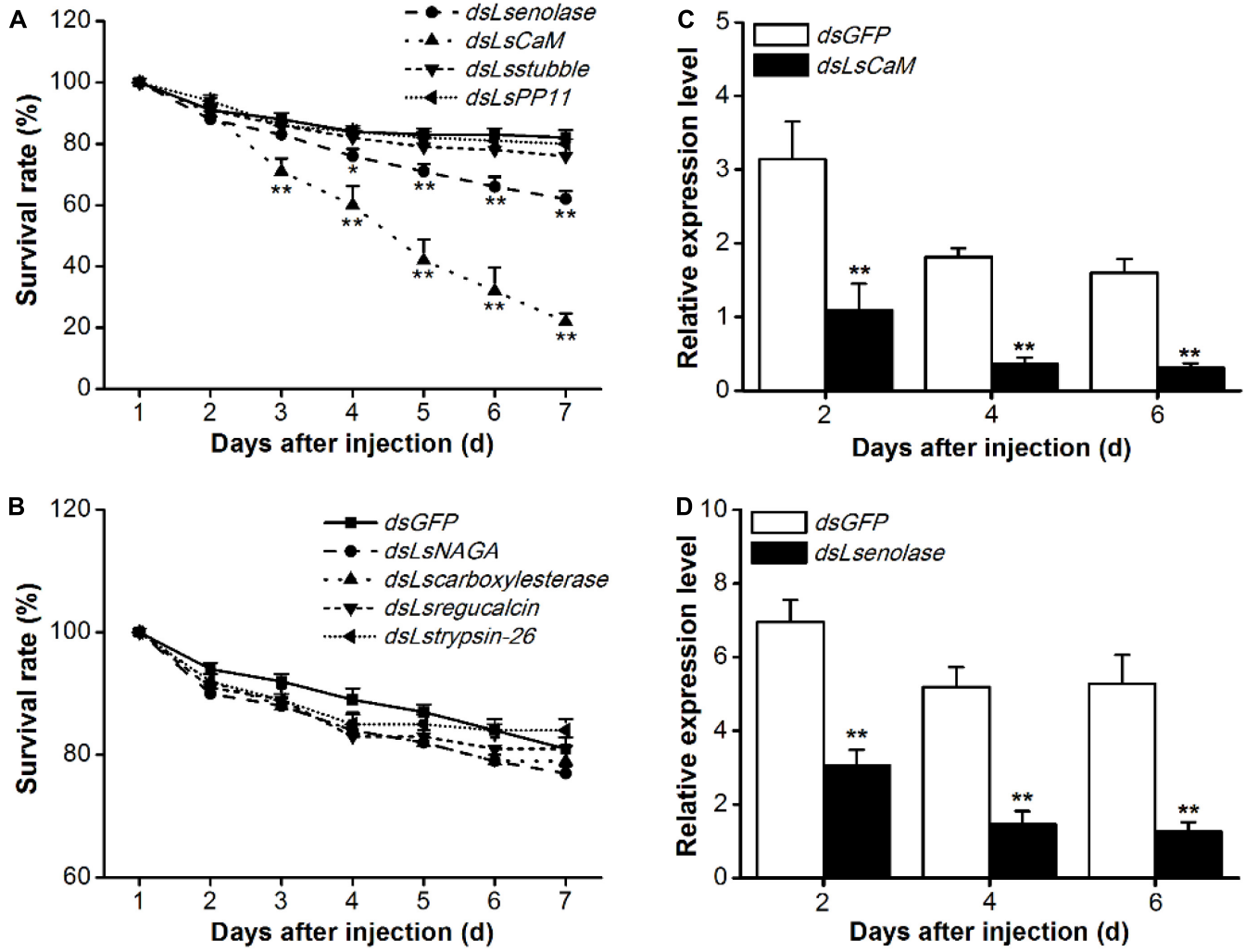

FIGURE 1 | Effects of silencing salivary protein-encoding genes on survival rates of SBPH on rice. (A,B) Mean survival rates + SE $(n=5)$ of SBPH nymphs injected with dsRNA of indicated genes or GFP (dsGFP) at third-instar nymph stage. CaM, calmodulin; PP11, placental protein 11; NAGA, $\alpha$ - N-acetylgalactosaminidase. (C,D) Mean transcript levels + SE $(n=3)$ of indicated target genes in SBPH injected with dsRNA of LSCaM (dsLsCaM, C), Lsenolase (dsLsenolase, D), or dsGFP. Asterisks indicate significant reduction in survival rates $\mathbf{( A , B )}$ and gene expression levels $\mathbf{( C , D )}$ of SBPH injected with dsLsCaM or dsLsenolase compared with those injected with dsGFP $\left({ }^{\star} P<0.05,{ }^{\star \star} P<0.01\right.$; Student's $t$-tests).

lethal to SBPH (Figure 1). Compared with the dsGFPinjected SBPH nymphs, the dsLsenolase-injected and dsLsCaM-injected nymphs presented with significantly lower survival rates 3 and 4 days after dsRNA injection, respectively. At 7 days post-injection, their survival rates were 22 and 62\%, respectively (Figure 1A). By contrast, suppression of the other six salivary protein-encoding genes did not cause any abnormalities in the SBPH nymphs (Figures 1A,B).

The qPCR analysis confirmed that the expression levels of all eight genes were markedly lower in the RNAi-treated SBPH nymphs than in the $d s G F P$-injected nymphs (Figures 1C,D and Supplementary Figure 1). The Lsenolase and LsCaM transcript levels were $\sim 70 \%$ lower at 2-6 days post-injection (Figures 1C,D).

\section{Knocking Down LsCaM Impairs Small Brown Planthopper Feeding and Fecundity}

To investigate whether Lsenolase and LsCaM are effectors, we used the EPG technique to study the effects of knocking down LsCaM and Lsenolase on SBPH feeding. EPG profiles the feeding behavior of piercing-sucking insects (Seo et al., 2009; Ji et al., 2017) and distinguishes the non-penetration (NP), pathway (penetration initiation, salivation, stylet movement, and extracellular activity near the phloem; PP), the phloem (N4), and the xylem (N5) phases. LsCaM silencing significantly prolonged NP and PP but significantly shortened N4 (Figure 2A). Silencing LsCaM also significantly reduced honeydew excretion (Figure 2B). Hence, food intake had decreased. By contrast, silencing Lsenolase affected neither the feeding behavior nor the amount of honeydew excreted (Figures 2A,B). Taken together, these results suggest that $\mathrm{LsCaM}$ is required for $\mathrm{SBPH}$ feeding, whereas enolase is not. The number of eggs laid by the LsCaMsilenced female was $82 \%$ lower than those laid by the $d s G F P$ injected female (Figure 2C).

\section{Sequence Analysis of Calmodulin From Brown Planthopper and Small Brown Planthopper}

A BLAST analysis revealed that the CORF of SBPH LsCaM had $96 \%$ identity with the CORF of the previous reported 


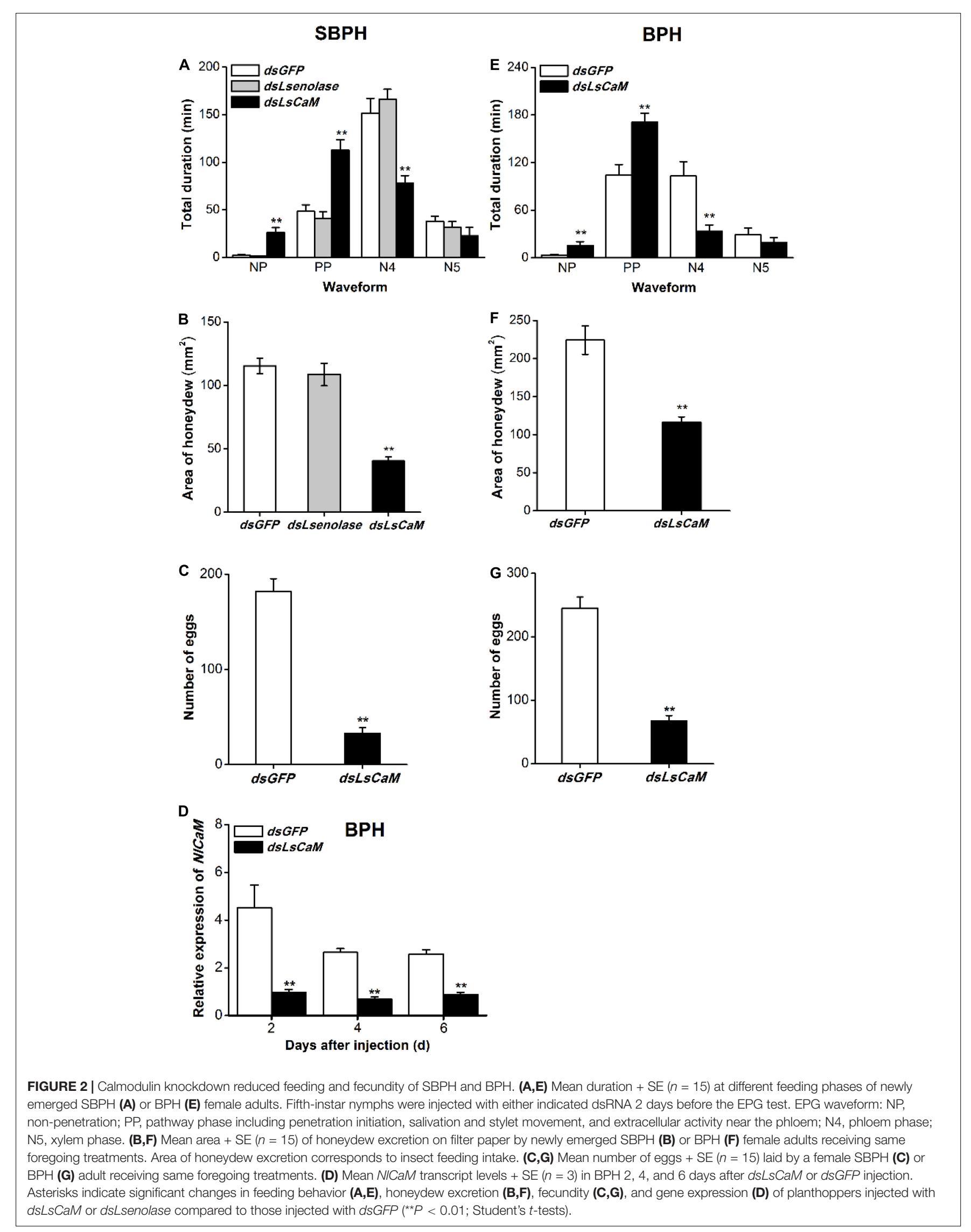


BPH NlCaM (Wang et al., 2018; Supplementary Figure 2A). Nevertheless, they had identical protein sequences. Thus, we used dsRNA synthesized from the LsCaM CORF sequence to knock down BPH NlCaM. Injection with dsLsCaM downregulated BPH NlCaM by $66-79 \%$ at 2-6 days post-injection (Figure 2D). Therefore, high RNAi efficiency of BPH NlCaM was achieved through $d s L s C a M$ injection.

\section{Calmodulin Enhances Brown Planthopper Performance}

Consistent with the above finding on $\mathrm{SBPH}$, relative to the $d s G F P$ control, dsLsCaM injection into $\mathrm{BPH}$ significantly extended NP and PP but shortened N4 (Figure 2E). Silencing NlCaM (dsLsCaM) reduced by $35 \%$ the amount of honeydew excreted by $\mathrm{BPH}$ (Figure 2F). Moreover, the fecundity of NlCaMsilenced BPH female adult (dsLsCaM) had declined by $73 \%$ (Figure 2G). Thus, NlCaM is also implicated in $\mathrm{BPH}$ feeding, fecundity, and survival.

\section{Calmodulin Is Indispensable for Small Brown Planthopper and Brown Planthopper Survival on Rice}

To test whether CaM influenced the SBPH and BPH survival on rice and whether this influence was related to the role of $\mathrm{CaM}$ in the planthopper-rice interaction, we compared the survival rate of nymphs feeding on different food matrices. $\mathrm{CaM}$ silencing generally reduced the survival rate of $\mathrm{SBPH}$ and $\mathrm{BPH}$ (Figure 3), and the effect was most pronounced on rice plants: 3 days after dsRNA injection, the survival rate of $\mathrm{SBPH}$ and $\mathrm{BPH}$ nymphs on rice dropped significantly, and it was $24 \%(\mathrm{SBPH})$ and $32 \%(\mathrm{BPH})$ at 7 days (Figures $\mathbf{3 A}, \mathbf{B})$. In contrast, the survival rate of nymphs with knocked down CaM was higher in insects raised on artificial diet than in those raised on rice; moreover, the survival rate of nymphs with silenced $C a M$ raised on artificial diet was reduced slightly compared with that of control nymphs 5 days after the start of the experiment (Figures 3C,D). Compared with that of nymphs with silenced $C a M$ raised on artificial diet, the corrected survival rate of nymphs with silenced CaM raised on rice was significantly lower 4-7 days post-injection (Figures 3E,F). These results demonstrate that CaM contributes to the survival of SBPH and $\mathrm{BPH}$ nymphs raised on rice.

\section{Calmodulin Characterization}

Spatial expression analysis revealed that $\mathrm{BPH}$ and $\mathrm{SBPH} C a M$ were expressed in all tissues examined and highly expressed in salivary glands (Figures 4A,B). Temporal expression pattern revealed that $\mathrm{BPH}$ and $\mathrm{SBPH} C a M$ were expressed at all developmental stages (Figures 4C,D).

Calmodulin protein comprises 149 amino acids, and its molecular mass is $16.81 \mathrm{kDa}$. Previous studies showed that four and five unique peptides were detected in the $\mathrm{CaM}$ proteins derived from $\mathrm{BPH}$ and $\mathrm{SBPH}$ watery saliva proteomes, respectively (Huang et al., 2018; Fu et al., 2021; Supplementary Figure 2B). We hypothesized that $\mathrm{BPH}$ and $\mathrm{SBPH}$ secrete $\mathrm{CaM}$ as they feed on rice. We performed a western blot analysis to test this hypothesis. The antibody revealed $\sim 16 \mathrm{kDa}$ bands in plants grazed by $\mathrm{BPH}$ or $\mathrm{SBPH}$ nymphs (Figures 4E,F; lane 3). These bands were absent in uninfested control plants (Figures 4E,F; lane 2). The same bands were also detected in $\mathrm{BPH}$ and $\mathrm{SBPH}$ salivary gland extracts (Figures 4E,F; lane 1). Hence, CaM is transferred from $\mathrm{BPH}$ and $\mathrm{SBPH}$ salivary glands to the host plant during feeding.

The CaM protein had no extracellular signal peptides or transmembrane domains but contained four EF-hand $\mathrm{Ca}^{2+}$ binding domains (Supplementary Figure 2B). We conducted an electrophoretic mobility shift assay to determine the $\mathrm{Ca}^{2+}$ binding capacity of the CaM protein. Recombinant CaM was produced in an E. coli expression system, mixed with various $\mathrm{CaCl}_{2}$ concentrations, and subjected to sodium dodecyl sulfatepolyacrylamide gel electrophoresis (SDS-PAGE). CaM mobility was lower in the presence of $0.015-0.5 \mathrm{mM} \mathrm{CaCl}_{2}$ than it was in the presence of $0.5 \mathrm{mM}$ EDTA. Moreover, high $\mathrm{CaCl}_{2}$ concentrations impeded CaM migration (Figure 4G). Similar electrophoretic mobility shift patterns were reported for other $\mathrm{Ca}^{2+}$-binding proteins (Hattori et al., 2012; Ye et al., 2017; Tian et al., 2021), but not for the BSA control protein. When CaM-GFP fusion protein was transiently expressed in rice protoplasts or $N$. benthamiana leaves, GFP fluorescence was detected in the cytoplasms and nuclei (Figure $\mathbf{4 H}$ and Supplementary Figure 3).

\section{Transient Calmodulin Expression in planta Suppresses Plant Immune Responses}

Small brown planthopper salivary LsPDI1 is an elicitor that induces $\mathrm{Ca}^{2+}$-dependent cell death, reactive oxygen species burst, and callose deposition in plants (Fu et al., 2021). Transient CaM-GFP and LsPDI1-mCherry expression was performed in $N$. benthamiana leaves to determine whether CaM influences plant immune responses. CaMGFP expression significantly suppressed LsPDI1-induced cell death (Figure 5A), $\mathrm{H}_{2} \mathrm{O}_{2}$ accumulation (Figures 5B,C), and callose deposition (Figures 5D,E), whereas only GFP expression control did not (Figure 5). Taken together, these results imply that CaM may suppress plant immune responses by binding free $\mathrm{Ca}^{2+}$ in the plant cell cytoplasms and nuclei.

\section{Calmodulin Secretion Suppresses Planthopper-Induced Callose Deposition and $\mathrm{H}_{2} \mathrm{O}_{2}$ Accumulation in Rice}

We also measured callose deposition and $\mathrm{H}_{2} \mathrm{O}_{2}$ accumulation in rice plants infested with $d s G F P$ - or $d s L s C a M$-injected $\mathrm{BPH}$ or $\mathrm{SBPH}$ nymphs. Callose deposition and $\mathrm{H}_{2} \mathrm{O}_{2}$ concentration were significantly higher in the $d s L s C a M-\mathrm{BPH}$-infested rice plants than they were in the $d s G F P$-BPH-infested plants (Figures 6A,B,D). The same also was true for $\mathrm{SBPH}$ (Figures 6A,C,E). Thus, secreted $\mathrm{CaM}$ by $\mathrm{BPH}$ and 

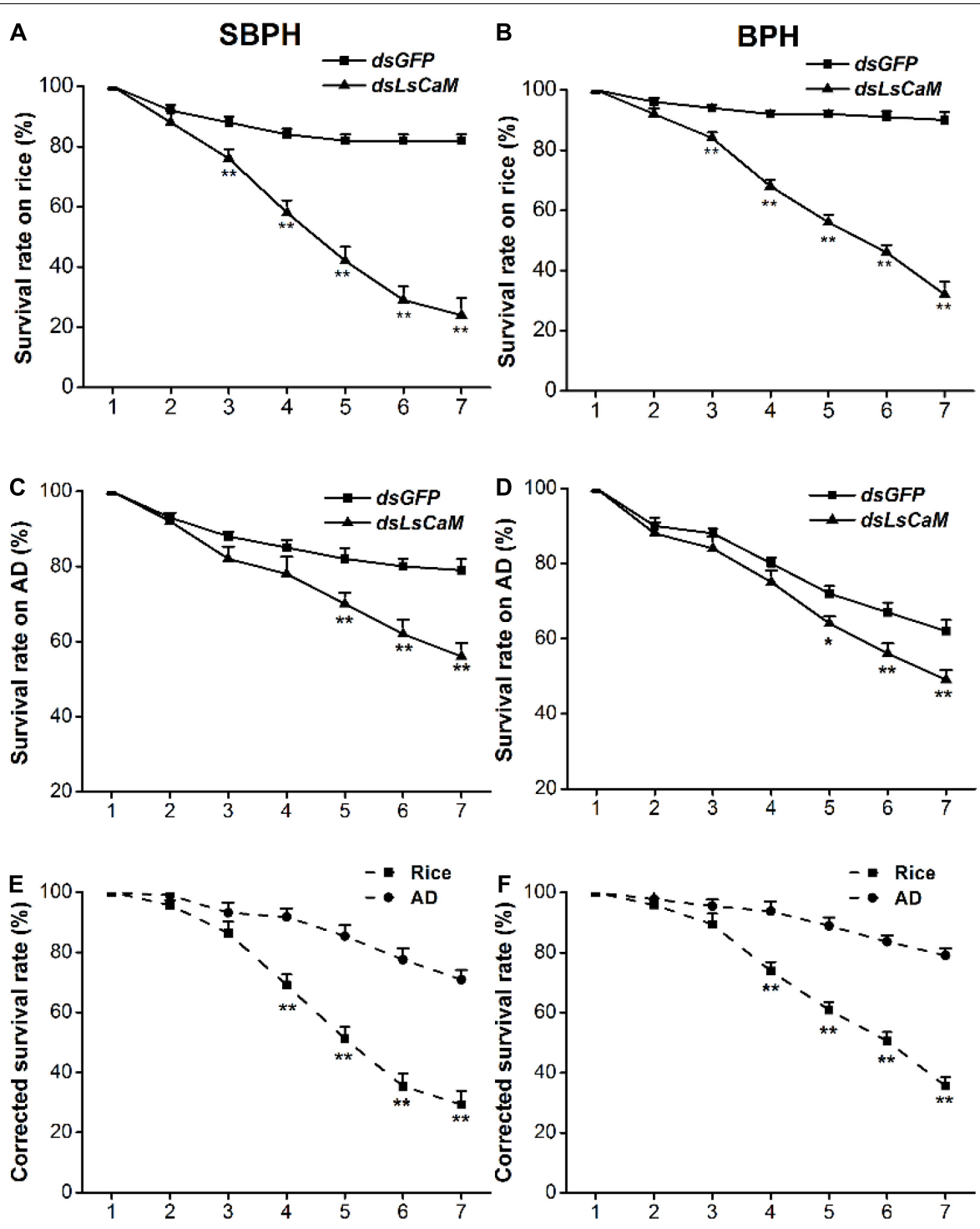

Days after injection (d)

FIGURE 3 | Knocking down CaM reduces survival rates among nymphs. (A-D) Mean survival rates + SE $(n=5)$ of SBPH and BPH nymphs injected with ds $L s C a M$ or dsGFP at third-instar nymph stage, fed on rice (A,B) or artificial diet (AD; C,D). (E,F) Mean corrected survival rates + SE $(n=5)$ of SBPH (E) and BPH (F) nymphs with injected dsLsCaM, using nymphs with injected dsGFP as controls, feeding on rice plants or artificial diet. Asterisks indicate significant differences between treatments $\left({ }^{\star} P<0.05,{ }^{\star *} P<0.01\right.$; Student's $t$-tests).

SBPH may suppress insect-induced callose deposition and $\mathrm{H}_{2} \mathrm{O}_{2}$ accumulation.

\section{DISCUSSION}

Calmodulin is a member of the EF-hand family of eukaryotic calcium-binding proteins. Previous study showed that the CaM contributed to BPH survival and female adult fecundity (Wang et al., 2018). However, its salivary distribution, $\mathrm{Ca}^{2+}$ affinity, and effector function in planthopper-plant interactions remain unknown. Analysis of saliva proteome and western blotting demonstrated that $\mathrm{BPH}$ and SBPH secreted CaM into rice during feeding. Subcellular localization indicated CaM was localized to the plant cytoplasms and nuclei. CaM mobility on SDS-PAGE gel was markedly reduced by increasing the $\mathrm{CaCl}_{2}$ concentration due to the $\mathrm{Ca}^{2+}$-binding capacity via four EF-hand motifs. This discovery was consistent with other salivary $\mathrm{Ca}^{2+}$-binding proteins comprising multiple EF-hand motifs (Hattori et al., 2012; Ye et al., 2017; Tian et al., 2021). Thus, CaM may bind free $\mathrm{Ca}^{2+}$ after it is injected along with planthopper saliva into plant tissues, then modulate host plant defenses.

The planthoppers salivary proteomes (Huang et al., 2018; Fu et al., 2021) demonstrated that only $\sim 25 \%$ of salivary proteins 
A

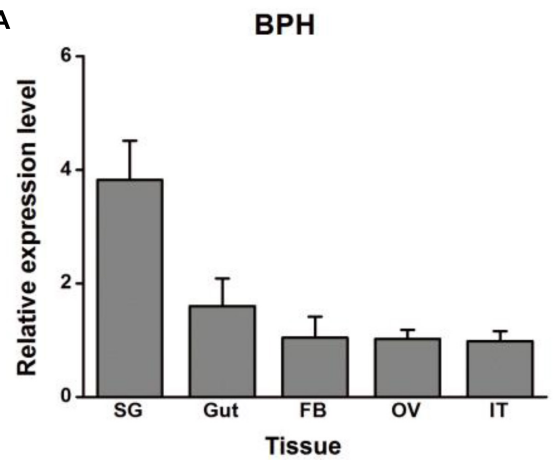

C

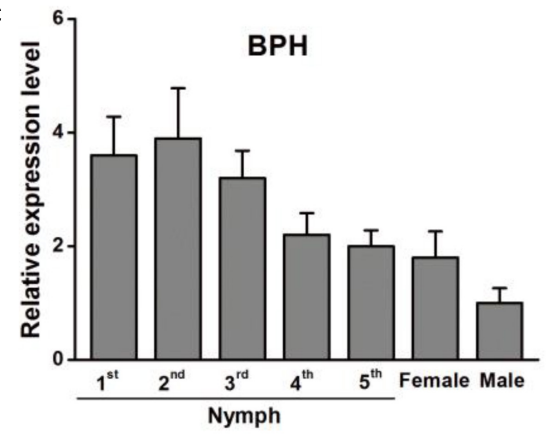

B
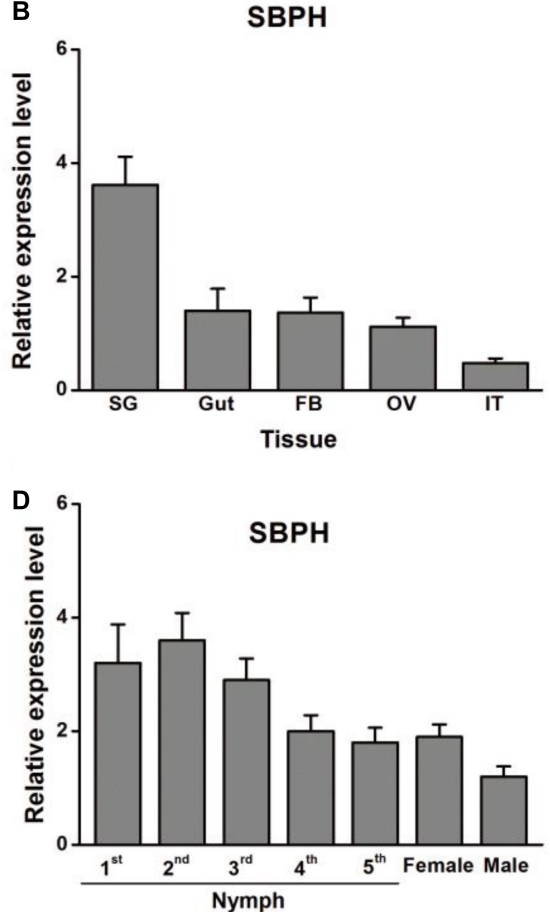

E

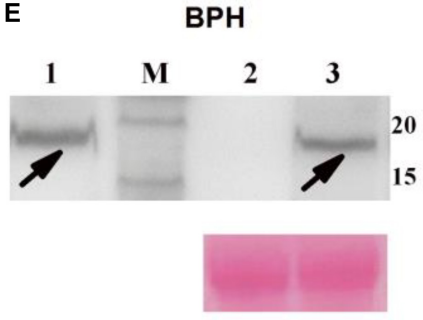

F SBPH

2

G
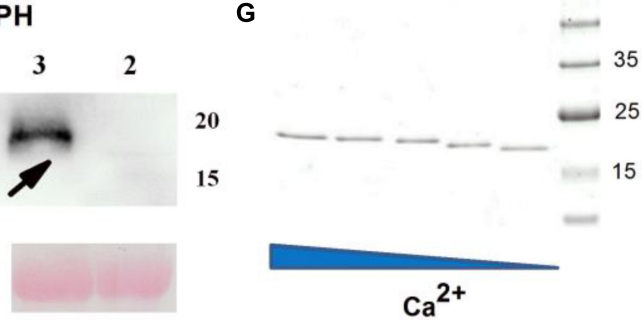

H

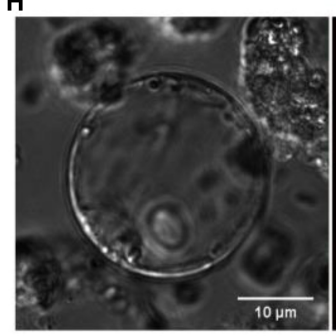

Bright

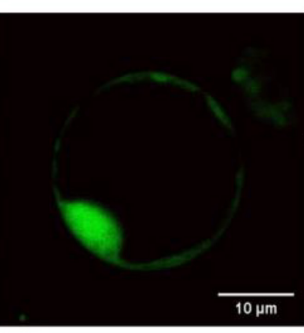

CaM-GFP

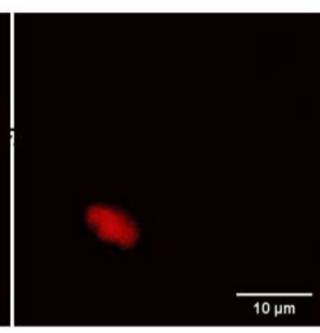

Nucleus-RFP

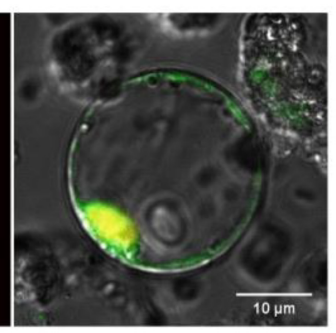

Merged

FIGURE 4 | Molecular characterization of CaM. (A-D) Mean transcript levels + SE $(n=3)$ of $L s C a M$ and $N / C a M$ in BPH (A,C) and SBPH (B,D) whole bodies at various developmental stages (A,B) and in various tissues (C,D). SG, salivary gland; OV, ovary; FB, fat body; IT, integument. (E,F) CaM secretion by BPH (E) or SBPH (F) into host rice. Western blot analysis of CaM. Lane 1 shows extracts of BPH (E) or SBPH (F) salivary glands. Lanes 2 and 3 represent extracts of uninfested control rice leaf sheaths (lane 2) or rice leaf sheaths infested with fifth-instar nymphs of BPH (E) or SBPH (F). M, molecular weight marker (kDa). Equal loading of plant samples (lanes 2 and 3) was indicated by Ponceau stained-Rubisco protein (PS). Black arrowheads indicate CaM target bands. (G) SDS-PAGE showing $\mathrm{Ca}^{2+}$-dependent mobility of recombinant protein CaM. Purified $\mathrm{CaM}$ was incubated at $25^{\circ} \mathrm{C}$ for $30 \mathrm{~min}$ as follows: lane $1,0.5 \mathrm{mM} \mathrm{CaCl}$; lane $2,0.15 \mathrm{mM}$ $\mathrm{CaCl}_{2}$; lane 3, $0.05 \mathrm{mM} \mathrm{CaCl}_{2}$; lane 4, $0.015 \mathrm{mM} \mathrm{CaCl}_{2}$; lane 5, $0.5 \mathrm{mM}$ EDTA. (H) Transiently expressed CaM was localized to rice cell cytoplasms and nuclei. CaM-GFP fusion protein was expressed in rice protoplasts by polyethylene glycol-mediated transformation. Protein distribution was investigated by confocal laser-scanning microscopy at $16 \mathrm{~h}$ after transformation. Bars $=10 \mu \mathrm{m}$.

contained an N-terminal signal peptide, which might be delivered into saliva through the eukaryotic endoplasmic reticulum Golgi pathway (Walter and Johnson, 1994). Although CaM don't have a signal peptide, western blotting confirmed that CaM is a salivary protein. However, whether many salivary proteins like CaM without signal peptides are secreted in an unconventional way 

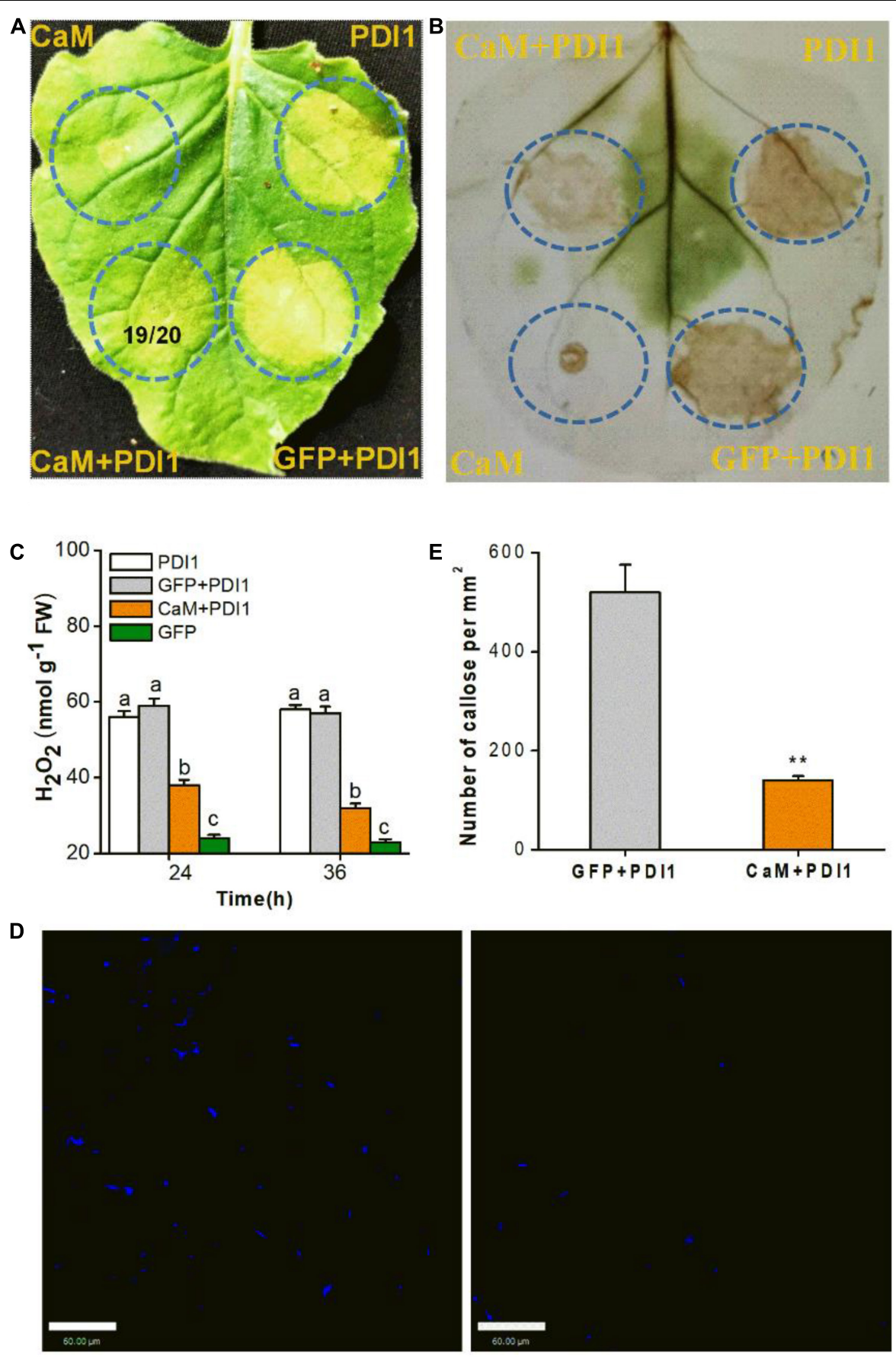

GFP+PDI1

CaM+PDI1

FIGURE 5 | Transient CaM expression suppresses cell death, $\mathrm{H}_{2} \mathrm{O}_{2}$ accumulation, and callose deposition in Nicotiana benthamiana leaves. (A) LsPDI1-induced cell death was observed in all leaf areas co-expressing GFP and LSPDI1. A ratio of 19/20 in the circle of representative leaf indicates cell death reduction in 19 leaf areas co-expressing CaM and LsPDI1 relative to 20 experimental leaves. N. benthamiana leaves were infiltrated with A. tumefaciens harboring GFP or CaM at $24 \mathrm{~h}$ before LsPDI1 expression in the same region. Experiment was repeated on 20 leaves. PDI1 indicates the SBPH salivary elicitor LsPDI1. (B) Mitigation of LsPDI1-triggered $\mathrm{H}_{2} \mathrm{O}_{2}$ accumulation in $\mathrm{N}$. benthamiana leaves by CaM and LsPDI1 co-expression. After DAB staining and decolorization, brown color intensity and area were commensurate with $\mathrm{H}_{2} \mathrm{O}_{2}$ level. LsPDI1-induced $\mathrm{H}_{2} \mathrm{O}_{2}$ accumulation apparent in leaf areas co-expressing GFP and LsPDI1. (C) Mean levels $+\mathrm{SE}(n=6)$ of $\mathrm{H}_{2} \mathrm{O}_{2}$ in infiltrated $\mathrm{N}$. benthamiana leaves receiving foregoing treatments. Experiment was repeated six times with $0.1 \mathrm{~g}$ infiltrated areas combined as a single sample. Different letters indicate significant difference among treatments $(P<0.05$; one-way ANOVA followed by Duncan's multiple range test). (D) Representative images of callose deposition in N. benthamiana leaves. Aniline blue staining of $N$. benthamiana leaves showing callose deposition (bright blue fluorescence) in areas transfected with GFP or CaM-GFP $24 \mathrm{~h}$ before LSPDI1 expression in the same region. Photographs were taken $72 \mathrm{~h}$ after infiltration. (E) Mean number of callose deposits + SE $(n=20)$ per $\mathrm{mm}^{2}$. N. benthamiana leaves received same foregoing treatments. Asterisks indicate significant changes $(P<0.01 ;$ Student's $t$-tests $)$. Bars $=60 \mu \mathrm{m}$. 


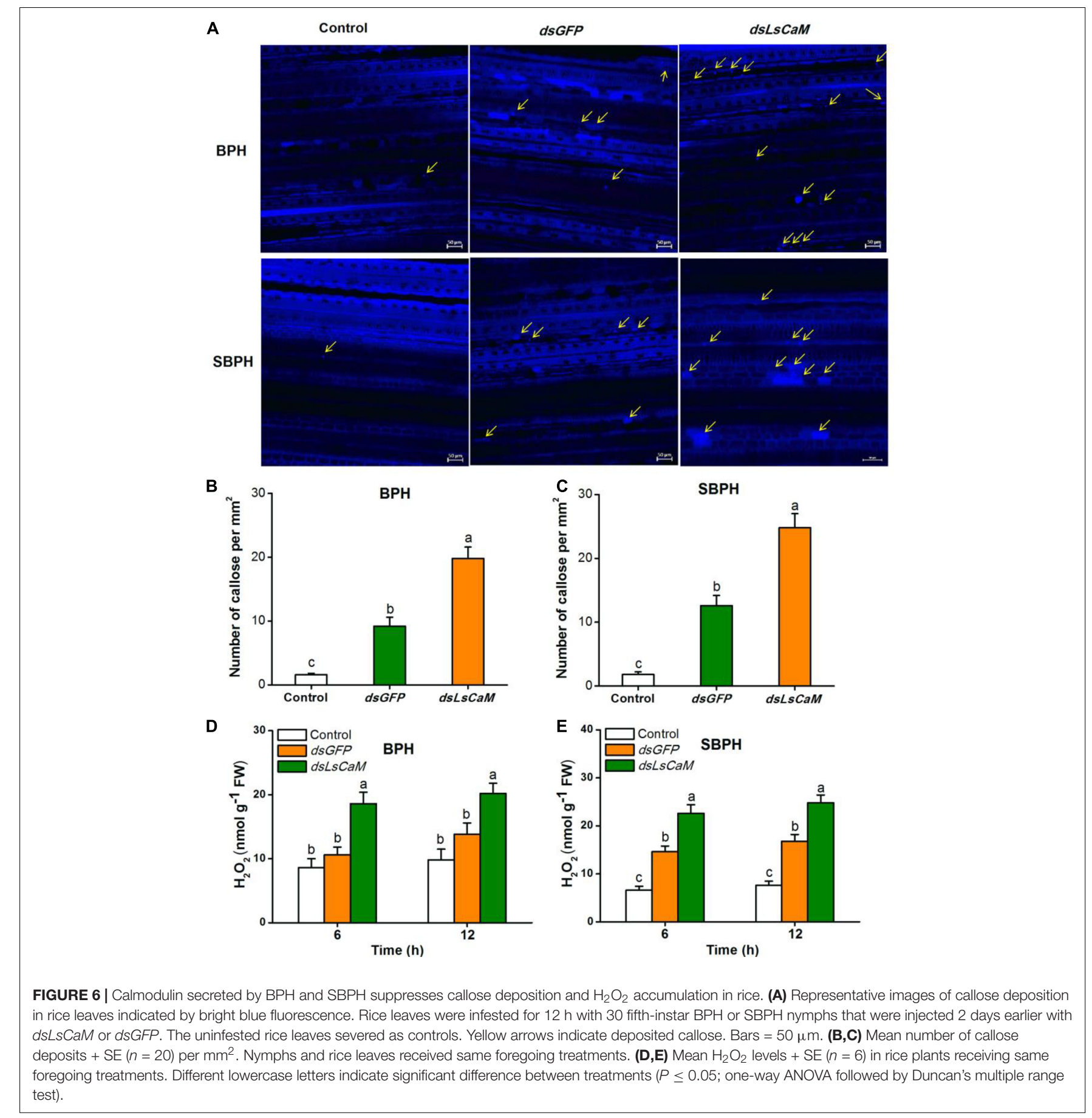

(Nickel and Rabouille, 2009) remains unknown. Transient and drastic elevation in plant cytosolic $\mathrm{Ca}^{2+}$ is markedly induced by diverse stimuli. In unstimulated plant cells, CaM localized to the cytoplasm and nuclei when transiently expressed. Thus, the binding of $\mathrm{CaM}$ and $\mathrm{Ca}^{2+}$ decreased free $\mathrm{Ca}^{2+}$ level in cytoplasm. This may interfere with the signal transduction from $\mathrm{Ca}^{2+}$ influx to specific defense responses. However, the function of $\mathrm{CaM}$ in the nuclei is unknown. The Arabidopsis $\mathrm{Ca}^{2+}$. dependent modulator of ICR1 (CMI1, $\mathrm{Ca}^{2+}$-binding protein) containing a EF-hand motif is localized in the plasma membrane, cytoplasm and nuclei, whereas the interaction between interactor of constitutively active ROP (ICR1) with CMI1 is $\mathrm{Ca}^{2+}$ dependent and make the latter be excluded from nuclei (Hazak et al., 2019). Thus, $\mathrm{CaM}$ binding $\mathrm{Ca}^{2+}$ or plant target protein also may affect its subcellular localization and function.

Elevation in cytosolic $\mathrm{Ca}^{2+}$ concentration is an early, vital defense-related signal. It activates downstream plant defense responses, such as $\mathrm{H}_{2} \mathrm{O}_{2}$ and callose biosynthesis 
(Hayashi et al., 1987; Zuppini et al., 2004). Callose deposition around sieve pores caused by sap-sucking insects penetrating was observed around the stylet puncture sites in rice sieve tubes, and could seal sieve pores, thereby preventing the loss of phloem sap (Hao et al., 2008). In response, insect secretes certain salivary effectors that manipulate the host plant defenses and facilitate feeding. An analogy is the mixture of salivary proteins that blood-feeding arthropods secrete to block hemostasis in their mammalian hosts. These salivary proteins inhibit platelet aggregation and blood coagulation, and ensure successful feeding. On the other hand, piercing-sucking herbivorous insects feed from sieve elements by circumventing or suppressing the host plant sieve plate sealing response. $\mathrm{Ca}^{2+}$-chelating agents such as EDTA prevent $\mathrm{H}_{2} \mathrm{O}_{2}$ and callose biosynthesis (Will et al., 2007). Analyses of saliva proteomes revealed that various $\mathrm{Ca}^{2+}$-binding proteins occur in several sap-sucking herbivorous insects, such as planthoppers, whiteflies, aphids, Asian citrus psyllids, and green rice leafhoppers (Huang et al., 2018; Huang H. J. et al., 2020; Fu et al., 2021). Therefore, salivary $\mathrm{Ca}^{2+}$ binding proteins may be ubiquitous among phloem feeders and perform a common function of suppression of callose deposition and $\mathrm{H}_{2} \mathrm{O}_{2}$ production, resembling that of EDTA. For instance, two salivary $\mathrm{Ca}^{2+}$-binding proteins, SBPH LsECP1 and $\mathrm{BPH}$ NISEF1, attenuate $\mathrm{Ca}^{2+}$-triggered $\mathrm{H}_{2} \mathrm{O}_{2}$ biosynthesis by binding free $\mathrm{Ca}^{2+}$ in host rice (Ye et al., 2017; Tian et al., 2021). Nevertheless, their functions of inhibition of callose deposition remain unknown.

Pathogen and insect infestation can induce $\mathrm{H}_{2} \mathrm{O}_{2}$ accumulation in plant that is harmful for the parasites. On the other hand, $\mathrm{H}_{2} \mathrm{O}_{2}$ acts as a common stress signal and triggers various plant defense responses such as programmed cell death, phytohormone biosynthesis and callose deposition (Kong et al., 2013; López-Cruz et al., 2017). Callose synthesis occurs at the site of $\mathrm{H}_{2} \mathrm{O}_{2}$ generation (Iwano et al., 2002), and $\mathrm{H}_{2} \mathrm{O}_{2}$ induces callose deposition, probably by activating expression of callose synthases (Bolwell et al., 2002). Expression of CaM in tobacco leaves could significantly inhibit callose deposition and $\mathrm{H}_{2} \mathrm{O}_{2}$ accumulation induced by the SBPH elicitor LsPDI1. When CaM-silenced planthoppers fed on rice plants, they were unable to suppress the callose deposition and $\mathrm{H}_{2} \mathrm{O}_{2}$ accumulation they had induced in the host plant by feeding on it. Consistent with the function of CaM, SBPH LsDNase II suppresses insect-elicited callose deposition and $\mathrm{H}_{2} \mathrm{O}_{2}$ accumulation in rice by degrading the extracellular DNA released by damaged plant cells (Huang et al., 2019). Aphid salivary effector Mp55 also suppresses the two foregoing defense responses [18]. Thus, CaM secreted by planthoppers may rapidly bind $\mathrm{Ca}^{2+}$ flowing into the sieve tubes in response to stylet puncturing and prevent increases in the sieve tube $\mathrm{Ca}^{2+}$ concentration. This mechanism may suppress the callose deposition directly, or inhibit the $\mathrm{H}_{2} \mathrm{O}_{2}$ signal biosynthesis, thereby preventing the downstream activation of callose deposition. In the future, the detailed molecular mechanism by which $\mathrm{CaM}$ governs $\mathrm{H}_{2} \mathrm{O}_{2}$ biosynthesis and callose synthases needs to be elucidated.

Knocking down CaM decreased the survival of SBPH and $\mathrm{BPH}$ fed on rice significantly. By contrast, the silencing did not affect the early ability of planthoppers to feed on artificial diet without callose and $\mathrm{H}_{2} \mathrm{O}_{2}$-mediated plant defense (i.e., for the first 5 days). Moreover, CaM is highly expressed in salivary glands of SBPH and BPH. These results suggest that CaM acts as a novel salivary effector to suppress defense responses in rice. Interestingly, CaM was also found to be expressed in all other tissues examined, suggesting that CaM may have other biological functions in planthoppers, i.e., the CaM may play roles in $\mathrm{BPH}$ nymphs and ovaries development (Wang et al., 2018). In other insects, silencing $\mathrm{CaM}$ affects the responsiveness of insects to odorants (Bahk and Jones, 2016). CaM also plays an important role in vitellogenesis and in the taste response of the sugar receptor (Brown et al., 2010; Brubaker-Purkey et al., 2013). Thus, $\mathrm{CaM}$ is likely to be a multifunction protein, and further research will be necessary to elucidate other roles in planthoppers.

The present study demonstrated that planthoppers secreted a classical $\mathrm{Ca}^{2+}$-binding salivary protein into the cells of the plants upon which they were feeding. This mechanism facilitated continuous feeding by suppressing host plant defense responses. Planthoppers use effector proteins to enhance their predation on plants by suppressing the $\mathrm{H}_{2} \mathrm{O}_{2}$ signaling pathway and callose deposition in the host. These findings lay theoretical and empirical foundations for breeding and propagating $\mathrm{CaM}$ dsRNA transgenic rice that are resistant to predation by sap-sucking insects. They also clarify the evolutionary mechanism by which insect salivary effectors suppress host plant immunity through "group warfare."

\section{DATA AVAILABILITY STATEMENT}

The original contributions presented in the study are included in the article/Supplementary Material, further inquiries can be directed to the corresponding authors.

\section{AUTHOR CONTRIBUTIONS}

RJ and JFa conceived the research. RJ, JFu, YS, LW, TT, JL, LG, $\mathrm{ZZ}$, and $\mathrm{MJ}$ performed the experiments, analyzed the data, and wrote the manuscript. All authors contributed to the article and approved the submitted version.

\section{FUNDING}

This study was sponsored by projects of the National Natural Science Foundation of China (31871965 and 31501636), the National Key Basic Research Program of China (2021YFD1401100), and the Jiangsu Agricultural Science and Technology Independent Innovation Fund [CX(20)3127 and CX(20)1004].

\section{SUPPLEMENTARY MATERIAL}

The Supplementary Material for this article can be found online at: https://www.frontiersin.org/articles/10.3389/fpls.2022. 841378/full\#supplementary-material 


\section{REFERENCES}

Anisuzzaman, Islam, M. K., Miyoshi, T., Alim, M. A., Hatta, T., Yamaji, K., et al. (2010). Longistatin, a novel EF-hand protein from the ixodid tick Haemaphysalis longicornis, is required for acquisition of host blood-meals. Int. J. Parasitol. 40, 721-729. doi: 10.1016/j.ijpara.2009.11.004

Arimura, G., and Maffei, M. (2010). Calcium and secondary CPK signaling in plants in response to herbivore attack. Biochem. Biophys. Res. Commun. 400, 455-460. doi: 10.1016/j.bbrc.2010.08.134

Bahk, S., and Jones, W. D. (2016). Insect odorant receptor trafficking requires calmodulin. BMC Biol. 14:83. doi: 10.1186/s12915-016-0306-x

Bing, L., Li, J. F., Ao, Y., Qu, J., and Wang, H. B. (2012). Lysin motif-containing proteins LYP4 and LYP6 play dual roles in peptidoglycan and chitin perception in rice innate immunity. Plant Cell 24, 3406-3419. doi: 10.1105/tpc.112.102475

Bolwell, G. P., Bindschedler, L. V., Blee, K. A., Butt, V. S., Davies, D. R., Gardner, S. L., et al. (2002). The apoplastic oxidative burst in response to biotic stress in plants: a three-component system. J. Exp. Bot. 53, 1367-1376. doi: 10.1093/ jexbot/53.372.1367

Bos, J. I., Prince, D., Pitino, M., Maffei, M. E., Win, J., and Hogenhout, S. A. (2010). A functional genomics approach identifies candidate effectors from the aphid species Myzus persicae (green peach aphid). PLoS Genet. 6:e1001216. doi: 10.1371/journal.pgen.1001216

Brown, P. T., Herbert, P., and Woodruff, R. I. (2010). Vitellogenesis in Oncopeltus fasciatus: PLC/IP3, DAG/PK-C pathway triggered by CaM. J. Insect Physiol. 56, 1300-1305. doi: 10.1016/j.jinsphys.2010.04.006

Brubaker-Purkey, B. J., Woodruff, R. I, and Jurenka, R. J. (2013). Vitellogenesis in the fruit fly, Drosophila melanogaster: antag-onists demonstrate that the PLC, IP3/DAG, PK-C pathway is triggered by calmodulin. J. Insect Sci. 13:68. doi: 10.1673/031.013.6801

Cao, T. T., Lü, J., Lou, Y. G., and Cheng, J. A. (2013). Feeding-induced interactions between two rice planthoppers, Nilaparvata lugens and Sogatella furcifera (Hemiptera: Delphacidae): effects on feeding and honeydew excretion. Environ. Entomol. 42, 1281-1291. doi: 10.1603/EN12171

Chaudhary, R., Atamian, H. S., Shen, Z., Briggs, S. P., and Kaloshian, I. (2014). GroEL from the endosymbiont Buchnera aphidicola betrays the aphid by triggering plant defense. Proc. Natl. Acad. Sci. U.S.A. 111, 8919-8924. doi: 10.1073/pnas.1407687111

Chyla, B. J., Harb, J., Mantis, C., Riehm, J. J., Ross, J. A., Sun, Y., et al. (2019) Response to venetoclax in combination with low intensity therapy (LDAC or HMA) in untreated patients with acute myeloid leukemia patients with IDH, FLT3 and other mutations and correlations with BCL2 family expression. Blood 134:546.

Dong, Y., Jing, M., Shen, D., Wang, C., Zhang, M., Liang, D., et al. (2020). The mirid bug Apolygus lucorum deploys a glutathione peroxidase as a candidate effector to enhance plant susceptibility. J. Exp. Bot. 71, 2701-2712. doi: 10.1093/ jxb/eraa015

Elzinga, D. A., De Vos, M., and Jander, G. (2014). Suppression of plant defenses by a Myzus persicae (green peach aphid) salivary effector protein. Mol. Plant Microbe Interact. 27, 747-756. doi: 10.1094/MPMI-01-14-0018-R

Fu, J., Shi, Y., Wang, L., Zhang, H., Li, J., Fang, J., et al. (2021). Planthopper-secreted salivary disulfide isomerase activates immune responses in plants. Front. Plant Sci. 11:622513. doi: 10.3389/fpls.2020.622513

Guo, H., Zhang, Y., Tong, J., Ge, P., Wang, Q., Zhao, Z., et al. (2020). An aphidsecreted salivary protease activates plant defense in phloem. Curr. Biol. 30, 4826-4836.e7.

Hao, P., Liu, C., Wang, Y., Chen, R., Tang, M., Du, B., et al. (2008). Herbivoreinduced callose deposition on the sieve plates of rice: an important mechanism for host resistance. Plant Physiol. 146, 1810-1820. doi: 10.1104/pp.107.111484

Hattori, M., Nakamura, M., Komatsu, S., Tsuchihara, K., Tamura, Y., and Hasegawa, T. (2012). Molecular cloning of a novel calcium-binding protein in the secreted saliva of the green rice leafhopper Nephotettix cincticeps. Insect Biochem. Mol. Biol. 42, 1-9. doi: 10.1016/j.ibmb.2011.10.001

Hayashi, T., Read, S., Bussell, J., Thelen, M., Lin, F.-C., Brown, R. Jr., et al. (1987). UDP-glucose:( $1 \rightarrow 3)-\beta$-glucan synthases from mung bean and cotton: differential effects of $\mathrm{Ca} 2+$ and $\mathrm{Mg} 2+$ on enzyme properties and on macromolecular structure of the glucan product. Plant Physiol. 83, 1054-1062. doi: $10.1104 / \mathrm{pp} .83 .4 .1054$
Hazak, O., Mamon, E., Lavy, M., Sternberg, H., Behera, S., Schmitz-Thom, I., et al. (2019). A novel Ca2+-binding protein that can rapidly transduce auxin responses during root growth. PLoS Biol. 17:e3000085. doi: 10.1371/journal. pbio. 3000085

Huang, H. J., Cui, J. R., Xia, X., Chen, J., Ye, Y. X., Zhang, C. X., et al. (2019). Salivary DN ase II from Laodelphax striatellus acts as an effector that suppresses plant defence. New Phytol. 224, 860-874. doi: 10.1111/nph.15792

Huang, H. J., Liu, C. W., Huang, X. H., Zhou, X., Zhuo, J. C., Zhang, C. X., et al. (2016). Screening and Functional Analyses of Nilaparvata lugens Salivary Proteome. J. Proteome Res. 15:1883. doi: 10.1021/acs.jproteome.6b00086

Huang, H. J., Ye, Z. X., Lu, G., Zhang, C. X., Chen, J. P., and Li, J. M. (2020). Identification of salivary proteins in the whitefly Bemisia tabaci by transcriptomic and LC-MS/MS analyses. Insect Sci. 28, 1369-1381. doi: 10. 1111/1744-7917.12856

Huang, H.-J., Lu, J.-B., Li, Q., Bao, Y.-Y., and Zhang, C.-X. (2018). Combined transcriptomic/proteomic analysis of salivary gland and secreted saliva in three planthopper species. J. Proteomics 172, 25-35. doi: 10.1016/j.jprot.2017.11.003

Huang, J., Zhang, N., Shan, J., Peng, Y., Guo, J., Zhou, C., et al. (2020). Salivary protein 1 of brown planthopper is required for survival and induces immunity response in plants. Front. Plant Sci. 11:571280. doi: 10.3389/fpls.2020.571280

Iwano, M., Che, F. S., Goto, K., Tanaka, N., Takayama, S., and Isogai, A. (2002). Electron microscopic analysis of the $\mathrm{H}_{2} \mathrm{O}_{2}$ accumulation preceding hypersensitive cell death induced by an incompatible strain of Pseudomonas avenae in cultured rice cells. Mol. Plant Pathol. 3, 1-8. doi: 10.1046/j.1464-6722. 2001.00087.x

Ji, R., Fu, J., Shi, Y., Li, J., Jing, M., Wang, L., et al. (2021). Vitellogenin from planthopper oral secretion acts as a novel effector to impair plant defenses. New Phytol. 232, 802-817. doi: 10.1111/nph.17620

Ji, R., Ye, W., Chen, H., Zeng, J., Li, H., Yu, H., et al. (2017). A salivary endo- $\beta$-1, 4-glucanase acts as an effector that enables the brown planthopper to feed on rice. Plant Physiol. 173, 1920-1932. doi: 10.1104/pp.16.01493

Kong, L., Wang, F., Si, J., Feng, B., Zhang, B., Li, S., et al. (2013). Increasing in ROS levels and callose deposition in peduncle vascular bundles of wheat (Triticum aestivum L.) grown under nitrogen deficiency. J. Plant Interact. 8, 109-116.

Lei, J., Finlayson, S. A., Salzman, R. A., Shan, L., and Zhu-Salzman, K. (2014). BOTRYTIS-INDUCED KINASE1 modulates Arabidopsis resistance to green peach aphids via PHYTOALEXIN DEFICIENT4. Plant Physiol. 165, 16571670. doi: 10.1104/pp.114.242206

Liu, S., Ding, Z., Zhang, C., Yang, B., and Liu, Z. (2010). Gene knockdown by intro-thoracic injection of double-stranded RNA in the brown planthopper, Nilaparvata lugens. Insect Biochem. Mol. Biol. 40, 666-671. doi: 10.1016/j.ibmb. 2010.06.007

López-Cruz, J., Óscar, C. S., Emma, F. C., Pilar, G. A., and Carmen, G. B. (2017). Absence of $\mathrm{Cu}-\mathrm{Zn}$ superoxide dismutase BCSOD1 reduces Botrytis cinerea virulence in Arabidopsis and tomato plants, revealing interplay among reactive oxygen species, callose and signalling pathways. Mol. Plant Pathol. 18, 16-31. doi: 10.1111/mpp.12370

Lou, Y., and Baldwin, I. T. (2006). Silencing of a germin-like gene in Nicotiana attenuata improves performance of native herbivores. Plant Physiol. 140, 11261136. doi: 10.1104/pp.105.073700

Nickel, W., and Rabouille, C. (2009). Mechanisms of regulated unconventional protein secretion. Nat. Rev. Mol. Cell Biol. 10, 148-155. doi: 10.1038/nrm2617

Otuka, A., Matsumura, M., Sanada-Morimura, S., Takeuchi, H., Watanabe, T., Ohtsu, R., et al. (2010). The 2008 overseas mass migration of the small brown planthopper, Laodelphax striatellus, and subsequent outbreak of rice stripe disease in western Japan. Appl. Entomol. Zool. 45, 259-266.

Ranf, S., Eschenlippold, L., Pecher, P., Lee, J., and Scheel, D. (2011). Interplay between calcium signalling and early signalling elements during defence responses to microbe- or damage-associated molecular patterns. Plant J. 68, 100-113. doi: 10.1111/j.1365-313X.2011.04671.x

Rao, W., Zheng, X., Liu, B., Guo, Q., Guo, J., Wu, Y., et al. (2019). Secretome analysis and in planta expression of salivary proteins identify candidate effectors from the brown planthopper Nilaparvata lugens. Mol. Plant Microbe Interact. 32, 227-239. doi: 10.1094/MPMI-05-18-0122-R

Rasool, B., McGowan, J., Pastok, D., Marcus, S. E., Morris, J. A., Verrall, S. R., et al. (2017). Redox control of aphid resistance through altered cell wall composition and nutritional quality. Plant Physiol. 175, 259-271. doi: 10.1104/pp.17.00625 
Seo, B. Y., Kwon, Y. H., Jung, J. K., and Kim, G. H. (2009). Electrical penetration graphic waveforms in relation to the actual positions of the stylet tips of Nilaparvata lugens in rice tissue. J. Asia Pac. Entomol. 12, 89-95. doi: 10.1016/j. aspen.2009.02.002

Shangguan, X., Zhang, J., Liu, B., Zhao, Y., Wang, H., Wang, Z., et al. (2018). A mucin-like protein of planthopper is required for feeding and induces immunity response in plants. Plant Physiol. 176, 552-565. doi: 10.1104/pp.17. 00755

Su, Q., Peng, Z., Tong, H., Xie, W., Wang, S., Wu, Q., et al. (2019). A salivary ferritin in the whitefly suppresses plant defenses and facilitates host exploitation. J. Exp. Bot. 70, 3343-3355. doi: 10.1093/jxb/erz152

Tian, T., Ji, R., Fu, J., Li, J., Wang, L., Zhang, H., et al. (2021). A salivary calciumbinding protein from Laodelphax striatellus acts as an effector that suppresses defense in rice. Pest Manage. Sci. 77, 2272-2281. doi: 10.1002/ps.6252

Walter, P., and Johnson, A. E. (1994). Signal sequence recognition and protein targeting to the endoplasmic reticulum membrane. Annu. Rev. Cell Biol. 10, 87-119.

Wang, N., Zhao, P., Ma, Y., Yao, X., Sun, Y., Huang, X., et al. (2019). A whitefly effector Bsp9 targets host immunity regulator WRKY33 to promote performance. Philos. Trans. R. Soc. Lond. B Biol. Sci. 374:20180313. doi: 10.1098/ rstb.2018.0313

Wang, Q., Yuan, E., Ling, X., Zhu-Salzman, K., and Sun, Y. (2020). An aphid facultative symbiont suppresses plant defense by manipulating aphid gene expression in salivary glands. Plant Cell Environ. 43, 2311-2322. doi: 10.1111/ pce. 13836

Wang, W., Wan, P., Lai, F., Zhu, T., and Fu, Q. (2018). Double-stranded RNA targeting calmodulin reveals a potential target for pest management of Nilaparvata lugens. Pest Manage. Sci. 74, 1711-1719. doi: 10.1002/ps.4865

Will, T., Kornemann, S. R., Furch, A. C., Tjallingii, W. F., and van Bel, A. J. (2009). Aphid watery saliva counteracts sieve-tube occlusion: a universal phenomenon? J. Exp. Biol. 212, 3305-3312. doi: 10.1242/jeb.028514

Will, T., Tjallingii, W. F., Thonnessen, A., and Van Bel, A. J. E. (2007). Molecular sabotage of plant defense by aphid saliva. Proc. Natl. Acad. Sci. U.S.A. 104, 10536-10541. doi: 10.1073/pnas.0703535104

Xu, H.-X., Qian, L.-X., Wang, X.-W., Shao, R.-X., Hong, Y., Liu, S.-S., et al. (2019). A salivary effector enables whitefly to feed on host plants by eliciting salicylic acid-signaling pathway. Proc. Natl. Acad. Sci. U.S.A. 116, 490-495. doi: 10.1073/pnas.171499 0116

Ye, W., Yu, H., Jian, Y., Zeng, J., Ji, R., Chen, H., et al. (2017). A salivary EFhand calcium-binding protein of the brown planthopper Nilaparvata lugens functions as an effector for defense responses in rice. Sci. Rep. 7:40498. doi: 10.1038/srep40498

Zhang, Y., Su, J., Duan, S., Ao, Y., Dai, J., Liu, J., et al. (2011). A highly efficient rice green tissue protoplast system for transient gene expression and studying light/chloroplast-related processes. Plant Methods 7:30. doi: 10.1186/17464811-7-30

Zhou, G., Qi, J., Ren, N., Cheng, J., Erb, M., Mao, B., et al. (2009). Silencing OsHI-LOX makes rice more susceptible to chewing herbivores, but enhances resistance to a phloem feeder. Plant J. 60, 638-648. doi: 10.1111/j.1365-313X. 2009.03988.x

Zuppini, A., Baldan, B., Millioni, R., Favaron, F., Navazio, L., and Mariani, P. (2004). Chitosan induces $\mathrm{Ca}^{2+}$-mediated programmed cell death in soybean cells. New Phytol. 161, 557-568. doi: 10.1046/j.1469-8137.2003.00969.x

Conflict of Interest: The authors declare that the research was conducted in the absence of any commercial or financial relationships that could be construed as a potential conflict of interest.

Publisher's Note: All claims expressed in this article are solely those of the authors and do not necessarily represent those of their affiliated organizations, or those of the publisher, the editors and the reviewers. Any product that may be evaluated in this article, or claim that may be made by its manufacturer, is not guaranteed or endorsed by the publisher.

Copyright (C) 2022 Fu, Shi, Wang, Tian, Li, Gong, Zheng, Jing, Fang and Ji. This is an open-access article distributed under the terms of the Creative Commons Attribution License (CC BY). The use, distribution or reproduction in other forums is permitted, provided the original author(s) and the copyright owner(s) are credited and that the original publication in this journal is cited, in accordance with accepted academic practice. No use, distribution or reproduction is permitted which does not comply with these terms. 